\title{
Correction of marked sagittal deformity with circumferential minimally invasive surgery using oblique lateral interbody fusion in adult spinal deformity
}

\author{
Seung Won Park ${ }^{1 *}$, Myeong Jin Ko ${ }^{1}$, Young Baeg Kim ${ }^{1}$ and Jean Charles Le Huec ${ }^{2}$
}

\begin{abstract}
Background: Spinal surgery performed entirely with minimally invasive surgery is referred to as circumferential MIS (cMIS). However, cMIS still has a limited sagittal correction capability for adult spinal deformity (ASD) with a marked sagittal deformity. We investigated the effectiveness of cMIS using oblique lateral interbody fusion (OLIF) and percutaneous posterior spine fixation in correcting marked sagittal deformity.

Methods: This study retrospectively evaluated 23 patients with ASD with marked sagittal deformity who underwent cMIS using OLIF without osteotomy and were followed-up for at least 24 months (whole group). The whole group was divided into the following two groups according to the type of interbody fusion at L5-S1: the OLIF51 group $(n=13)$ underwent OLIF at L1-L5 and L5-S1 and the TLIF51 group $(n=10)$ underwent OLIF at L1-L5 and transforaminal lumbar interbody fusion (TLIF) at L5-S1.

Results: Sagittal vertebral axis (SVA; 125.7 vs. $29.5 \mathrm{~mm}, p<0.001$ ), lumbar lordosis (LL; 18.2 $2^{\circ}$ vs. $51.7^{\circ}, p<0.001$ ), and pelvic incidence-LL mismatch (PI-LL, $35.5^{\circ}$ vs. $5.3^{\circ}$ ) significantly improved postoperatively in the whole group. The OLIF51 group showed significantly higher postoperative LL than the TLIF51 group (55.5 vs. $\left.46.9^{\circ}, p<0.001\right)$. OLIF yielded a significantly greater disc angle at L5-S1 than did TLIF $\left(18.4^{\circ}\right.$ vs. $\left.6.9^{\circ}, p<0.001\right)$. Proximal junctional kyphosis occurred significantly earlier in the OLIF51 group than in the TLIF51 group (8.6 vs. 26.3 months, $p<0.001$ ).

Conclusion: Successful sagittal correction in ASD patients with marked sagittal deformity was achieved with cMIS using OLIF. OLIF at L5-S1 showed a synergistic effect in sagittal deformity correction by CMIS.

Keywords: Adult spinal deformity, Marked sagittal deformity, Sagittal correction, Minimally invasive spine surgery, Oblique lateral interbody fusion, Percutaneous fixation
\end{abstract}

\section{Background}

Conventional deformity surgery, including open posterior or combined anterior-posterior approaches, is considered the standard technique for adult spinal deformity (ASD), with reliable clinical and radiological outcomes [1]. However, conventional deformity surgery is known to have a high risk of surgical complications, especially in patients with advanced age [2].

\footnotetext{
* Correspondence: nspsw@cau.ac.kr

1 Department of Neurosurgery, College of Medicine, Chung-Ang University,

102 Heukseok-ro, Dongjak-gu, Seoul 06973, Republic of Korea

Full list of author information is available at the end of the article
}

Minimally invasive surgery (MIS) can be an alternative surgical treatment with comparable surgical outcomes and lower complication rates [3-8]. Among various MIS techniques, transforaminal lumbar interbody fusion (TLIF), extreme lateral interbody fusion, or oblique lateral interbody fusion (OLIF) combined with percutaneous posterior spine fixation (PPSF) without any posterior osteotomy are important techniques for minimally invasive deformity $[3-6,8-10]$. Deformity correction using MIS techniques without any conventional open surgery is referred to as circumferential MIS (cMIS) [5, 11, 12]. Recently, OLIF at L5-S1 was introduced as a minimally invasive anterior approach and is

(c) The Author(s). 2020 Open Access This article is distributed under the terms of the Creative Commons Attribution 4.0 International License (http://creativecommons.org/licenses/by/4.0/), which permits unrestricted use, distribution, and 
expected to yield a greater lordotic angle at the L5-S1 level $[4,10]$. Although OLIF at L5-S1 is known to effectively improve the lordotic angle, no study has evaluated its effect on deformity correction [4]. Compared with conventional deformity surgery, cMIS is known to be effective for coronal but not for sagittal correction $[5-7,13,14]$. cMIS has been advanced continuously in sagittal correction of ASD [5, 6, 13]. Despite recent advancements, cMIS remains limited by the insufficient correction of marked sagittal deformity $[5,15,16]$.

Thus, this study aimed to investigate the effectiveness of cMIS using OLIF for ASD patients with marked sagittal deformity and analyzed the usefulness of OLIF at L5-S1.

\section{Methods}

\section{Patient population}

We retrospectively reviewed the medical records of consecutive patients who underwent surgery for degenerative spinal deformities at a single institute from December 2012 to December 2016. This study was approved by the Institutional Review Board of our hospital (1810-014-16217, 11/19/2018-11/18/2019). We enrolled ASD patients, aged 20 to 80 years old, who preoperatively satisfied the following three factors for sagittal imbalance: sagittal vertical axis (SVA) $>50 \mathrm{~mm}$, pelvic tilt $(\mathrm{PT})>20^{\circ}$, and pelvic incidence to lumbar lordosis mismatch (PI-LL) $>10^{\circ}$ [17-19]. We selected 23 patients based on the following inclusion criteria (whole group): (1) marked sagittal deformity preoperatively according to the SRS-Schwab sagittal modifier [19], (2) multilevel MIS lumbar interbody fusion ( $\geq 4$ levels including L5-S1) using OLIF at L1-L5 with TLIF or OLIF at L5-S1, (3) percutaneous fixation ( $\geq 5$ levels) including L5-S1 level, and (4) available follow-up evaluation for at least 24 months after surgery. We defined marked sagittal deformity as the presence of two or more marked sagittal modifiers, SVA $>9.5$ $\mathrm{cm}, \mathrm{PI}-\mathrm{LL}>20^{\circ}$, or PT $>30^{\circ}[19,20]$.

The whole group was divided into two groups according to the types of fusion technique at the L5-S1 level: (1) OLIF51 group $(n=13)$, which underwent OLIF at L1-L5 and OLIF at L5-S1 (Fig. 1) and (2) TLIF51 group $(n=10)$, which underwent OLIF at L1-L5 and TLIF at L5-S1 (Fig. 2). All patients received PPSF. The surgical goal was to achieve the following sagittal parameters: SVA $<50 \mathrm{~mm}, \mathrm{PT}<20^{\circ}$, and PI-LL $<10^{\circ}[19,21]$.

Patients who had undergone posterior corrective osteotomy or open posterior spine fixation were excluded. Other patients who underwent operation due to tumor, fracture, infection, or congenital anomalies were also excluded.

\section{Demographic data and clinical outcomes}

Demographic data included age, sex, American Society of Anesthesiologists (ASA) score, body mass index (BMI), Tscore of bone mineral density (BMD), follow-up period, surgical parameters, and clinical outcomes. Surgical parameters were surgical techniques, number of fusion or fixation levels, operation time, and estimated blood loss (EBL). Clinical outcomes were evaluated with visual analog scale (VAS) score for back or leg pain and Oswestry Disability

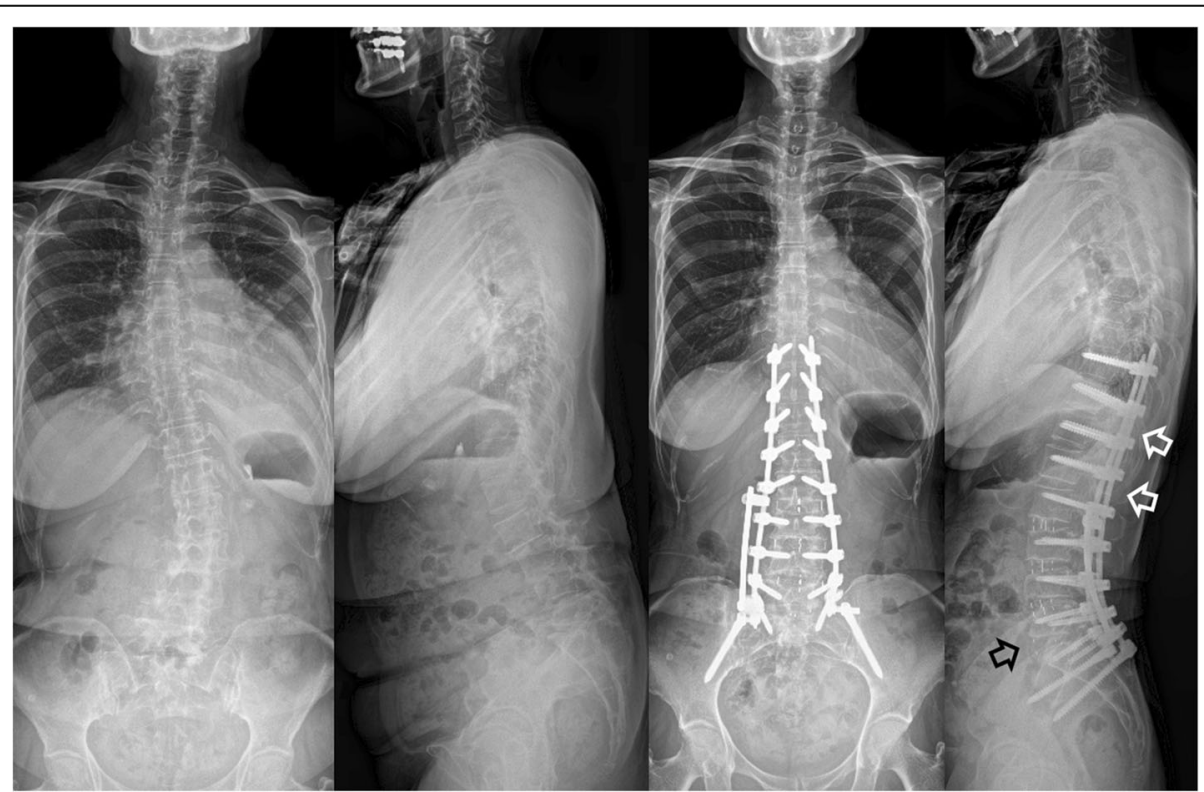

Fig. 1 A case in the OLIF51 group: marked sagittal deformity in a 70-year-old woman with adult spinal deformity. She underwent oblique lateral interbody fusion at L1-5 and L5-S1 (black arrow). Posterior fixation was performed with percutaneous pedicle screws and rods system without corrective osteotomy. A lordotic curve was noted at the thoracolumbar junction area (white arrows) 


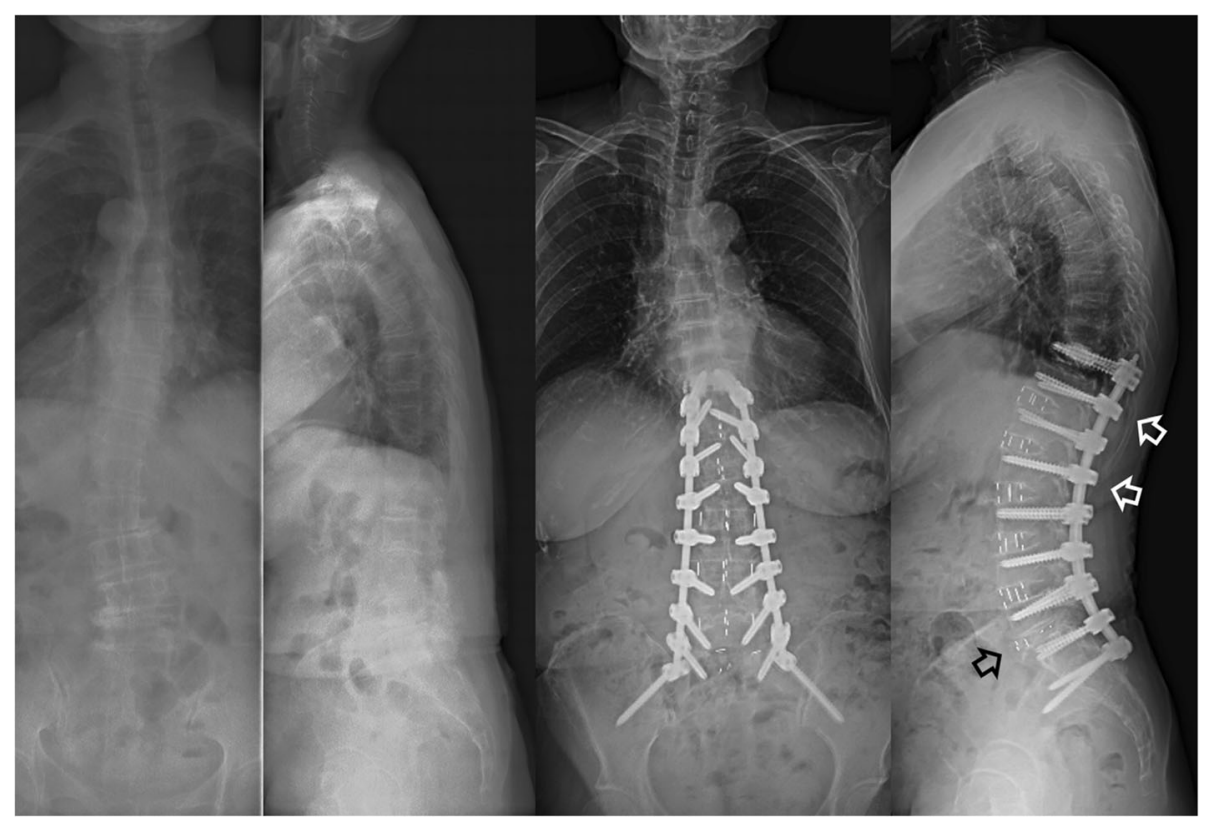

Fig. 2 A case in the TLIF51 group: marked sagittal deformity in a 65-year-old woman with adult spinal deformity. The patient underwent direct lateral lumbar interbody fusion at T12-L1, oblique lateral interbody fusion at L1-L5, and transforaminal lumbar interbody fusion at L5-S1 (black arrow). Posterior fixation was performed with percutaneous screws and rods system without corrective osteotomy. A lordotic curve was noted at the thoracolumbar junction area (white arrows)

Index (ODI), which were checked preoperatively and 24 months after surgery.

\section{OLIF at L1-L5 (Figs. 1 and 2)}

We performed OLIF at L1-L5 [10]. Patients were positioned in the right lateral decubitus position without hip flexion. A large rectangular polyether-ether ketone (PEEK) cage (Clydesdale, Medtronic, USA) with $6^{\circ}$ or $12^{\circ}$ lordotic angle and $20 \mathrm{~mm}$ width was inserted into the disc space. We used a $6^{\circ}$ cage for the L1-L3 levels and a $12^{\circ}$ cage for the L3-L5 levels to make a greater lordotic angle at the lower lumbar levels. The cage was filled with demineralized bone matrix (Grafton, Medtronic, USA) for bone fusion. We tried to insert the cages anteriorly close to the anterior disc margin for more posterior shortening by rod compression.

\section{OLIF at L5-S1 (Fig. 1)}

We performed OLIF at L5-S1 [10]. The patient position was the same as the position of OLIF at L1-L5. We inserted a round-shaped PEEK cage (Perimeter, Medtronic, USA) with $12^{\circ}$ lordotic angle into the center of the disc space in an oblique direction. Demineralized bone matrix (Grafton, Medtronic, USA) was also used as fusion material.

\section{TLIF at L5-S1 (Fig. 2)}

TLIF was performed at the L5-S1 level using a tubular retractor system (MAST Quadrant system, Medtronic,
USA) in the prone position [9]. We inserted two PEEK cages (Capstone, Medtronic, USA) into the disc space. The cages were packed with local bone chips from the lamina and facets.

\section{Percutaneous posterior spine fixation}

The patient was placed in the prone position with pillows under the chest and pelvis to make a natural lumbar lordotic curve. Posterior fixation was performed percutaneously (CD Horizon Longitude II system, Medtronic, USA) and connected to iliac screws (CD Horizon Legacy system, Medtronic, USA). The iliac screw was inserted through a small opening over the posterior superior iliac spine. Before rod insertion, we bent the motorized operation table to increase lumbar extension. We contoured the rods aggressively to create a greater lordotic curve. Rods were inserted from the iliac screws to the upper instrumented levels percutaneously. Finally, rod compression was done percutaneously for posterior shortening to further increase the lumbar lordotic angle.

\section{Radiological factors}

Various spinopelvic parameters were used for the evaluation of sagittal balance [19, 22]. Accordingly, we checked SVA, PT, PI, and LL at L1-S1; lower lumbar lordosis (LLL) at L4-S1, proportion of LLL in LL (LLL/LL, \%), PI-LL, and mean disc angles (DA) at L2-L5 and L5-S1. We checked the postoperative 
changes in LL (dLL) and SVA (dSVA). All radiological parameters were measured preoperatively and 24 months after surgery. Two observers (SWP and MJK) checked the radiological parameters two times with more than a 2-week interval.

\section{Complications}

Proximal junctional kyphosis (PJK) was assessed as a long-term radiological problem. PJK was defined according to two criteria: (1) the Cobb angle between the upper instrumented vertebra and two-level proximal vertebra was $\geq 10^{\circ}$ and (2) the proximal junctional Cobb angle was $10^{\circ}$ or more than the preoperative angle [23]. Other postoperative complications were also evaluated.

\section{Statistical analysis}

The non-parametric Mann-Whitney $U$ test and chisquare test were used for comparisons between groups. Preoperative and postoperative VAS scores were compared using the Wilcoxon signed rank test in each group and the Mann-Whitney $U$ test between two groups. A value of $p<0.05$ was considered as statistically significant. The intraobserver and interobserver intraclass correlation coefficients were calculated for the sagittal parameters and DA measured by the two observers [24].

\section{Results}

\section{Demographic data (Table 1)}

Thirty-seven consecutive ASD patients who underwent deformity correction surgery using MIS techniques (OLIF, TLIF, and PPSF) were investigated. Six patients were excluded because they received posterior corrective osteotomies. Three patients were lost to follow-up within 24 months after surgery. Five of 28 patients who underwent cMIS were excluded because their preoperative sagittal parameters did not satisfy the criteria for marked sagittal deformity. Finally, 23 ASD patients who had marked sagittal deformity preoperatively and underwent cMIS were enrolled (whole group). The number of patients in the OLIF51 and TLIF51 groups was 13 and 10 , respectively.

Table 1 Demographic data

\begin{tabular}{|c|c|c|c|}
\hline Parameters & Whole group & OLIF51 group & TLIF51 group \\
\hline No. patients & 23 & 13 & 10 \\
\hline Age & $69.4 \pm 5.0$ & $69.8 \pm 5.0$ & $68.9 \pm 5.3$ \\
\hline Female (\%) & $87.0 \%$ & $84.6 \%$ & $90.0 \%$ \\
\hline ASA score & $1.9 \pm 0.4$ & $1.9 \pm 0.3$ & $2.0 \pm 0.0$ \\
\hline BMl & $25.0 \pm 3.1$ & $26.0 \pm 3.8$ & $23.6 \pm 4.8$ \\
\hline BMD T-score & $-2.4 \pm 0.5$ & $-2.4 \pm 0.6$ & $-2.5 \pm 0.2$ \\
\hline Follow-up (months) & $40.7 \pm 14.6$ & $29.8 \pm 4.9^{* * *}$ & $54.8 \pm 9.8$ \\
\hline Fusion & OLIF, TLIF & OLIF at L1-S1 & OLIF at L1-L5, TLIF at L5-S1 \\
\hline Posterior fixation & Percutaneous & Percutaneous & Percutaneous \\
\hline No. fusion levels & $4.4 \pm 0.5$ & $4.4 \pm 0.5$ & $4.4 \pm 0.5$ \\
\hline No. fixation levels & $6.7 \pm 1.5$ & $6.8 \pm 1.5$ & $6.5 \pm 1.0$ \\
\hline Operation time (min) & $345.0 \pm 50.0$ & $347.9 \pm 60.9$ & $369.0 \pm 17.4$ \\
\hline $\mathrm{EBL}(\mathrm{ml})$ & $331.3 \pm 109.6$ & $260.7 \pm 83.5^{* * *}$ & $423.0 \pm 59.3$ \\
\hline \multicolumn{4}{|l|}{ Clinical outcomes } \\
\hline \multicolumn{4}{|l|}{ VAS Back } \\
\hline Before surgery & $6.5 \pm 1.5$ & $6.4 \pm 1.6$ & $6.6 \pm 1.5$ \\
\hline 24 months & $2.2 \pm 0.6 \neq$ & $2.1 \pm 0.6 \neq$ & $2.3 \pm 0.7 \ddagger$ \\
\hline \multicolumn{4}{|l|}{ VAS leg } \\
\hline Before surgery & $7.4 \pm 1.2$ & $7.6 \pm 1.1$ & $7.2 \pm 1.3$ \\
\hline 24 months & $1.4 \pm 0.8 \neq$ & $1.4 \pm 0.8 \neq$ & $1.3 \pm 0.7 \ddagger$ \\
\hline \multicolumn{4}{|l|}{ ODI } \\
\hline Before surgery & $49.9 \pm 7.7$ & $49.7 \pm 10.2$ & $50.1 \pm 4.2$ \\
\hline 24 months & $14.6 \pm 3.2 \neq$ & $14.9 \pm 3.3 \neq$ & $14.2 \pm 3.3 \neq$ \\
\hline
\end{tabular}

ASA score American Society of Anesthesiologists physical status classification (converted to an Arabic numeral for purposes of analysis), $B M I$ body mass index, $B M D$ bone mineral density, OLIF oblique lateral interbody fusion, TLIF transforaminal lumbar interbody fusion, EBL estimated blood loss, VAS visual analog scale, ODI Oswestry disability index

$\neq p<0.001$ compared to before surgery, ${ }^{* * *} p<0.001$ compared to TLIF51 group 
The mean age was $69.6 \pm 5.8$ years in the whole group. There was no significant difference between the OLIF51 and TLIF51 groups in the mean age and sex ratio.

The mean postoperative follow-up period was $40.7 \pm$ 14.6 (25-69) months in the whole group, and $29.8 \pm 4.9$ (25-37) and 54.8 $\pm 9.8(41-69)$ months in the OLIF51 and TLIF51 groups, respectively $(p<0.001)$. The significantly longer follow-up period of the TLIF51 group than the OLIF51 group was related with the later start of OLIF at L5-S1 in our hospital.

EBL during the surgery was $331.3 \pm 109.6 \mathrm{ml}$ in the whole group, which was significantly lower in the OLIF51 group than in the TLIF51 group $(260.7 \pm 83.5 \mathrm{ml}$ vs. $423.0 \pm 59.3 \mathrm{ml}, p<0.001)$.

The VAS and ODI scores significantly improved postoperatively in the whole group $(p<0.001)$. There was no significant difference in the pre- and postoperative VAS and ODI scores between the OLIF51 and TLIF51 groups.

\section{Radiological parameters (Table 2)}

The preoperative SVA, PT, LL, and PI-LL were $125.7 \pm$ $21.1 \mathrm{~mm}, 33.0 \pm 7.2^{\circ}, 18.2 \pm 9.0^{\circ}$, and $35.5 \pm 9.4^{\circ}$ in the whole group. The preoperative radiological parameters were not significantly different between the OLIF51 and TLIF51 groups.

In the whole group, the SVA $(29.5 \pm 14.8 \mathrm{~mm}, p<0.001)$, PT $\left(18.1 \pm 5.7^{\circ}, p<0.01\right)$, LL $\left(51.7 \pm 5.8^{\circ}, p<0.001\right)$, and PI-
LL $\left(5.3 \pm 3.6^{\circ}, \mathrm{p}<0.001\right)$ significantly improved postoperatively. Additionally, the OLIF51 group showed significantly higher LL $\left(55.5 \pm 2.8^{\circ}\right.$ vs. $\left.46.9 \pm 5.2^{\circ}, p<0.001\right)$ and significantly lower PI-LL $\left(3.6 \pm 3.0^{\circ}\right.$ vs. $\left.7.5 \pm 3.2^{\circ}, p<0.01\right)$ than the TLIF51 group.

Postoperative LLL at L4-S1 was greater in the OLIF51 than in the TLIF51 group $\left(31.1 \pm 1.4^{\circ}\right.$ vs. $\left.22.3 \pm 2.4^{\circ}, p<0.001\right)$. Hence, the postoperative proportion of LLL in the total LL (LLL/LL) was significantly greater in the OLIF51 than in the TLIF51 group $(56.2 \pm 2.1 \%$ vs. $47.8 \pm 4.9 \%, p<0.001)$.

In the whole group, dSVA and dLL were $96.2 \pm 23.4 \mathrm{~mm}$ (55.3-141.5) and $33.4 \pm 11.5^{\circ}(10.0-67.5)$, respectively. dLL was significantly greater in the OLIF51 than in the TLIF51 group $\left(38.7 \pm 10.2^{\circ}\right.$ vs. $\left.26.6 \pm 9.8^{\circ}, p<0.01\right)$.

The mean DA at L2 $-5\left(4.1 \pm 3.5^{\circ}\right.$ vs. $\left.12.4 \pm 1.5^{\circ}, p<0.001\right)$ and L5-S1 $\left(8.7 \pm 3.5^{\circ}\right.$ vs. $\left.12.9 \pm 6.7^{\circ}, p<0.01\right)$ significantly improved postoperatively in the whole group. Although there was no significant difference in the postoperative DA at L2-L5, postoperative DA at L5-S1 was significantly higher in the OLIF51 than in the TLIF51 group $\left(18.4 \pm 3.7^{\circ}\right.$ vs. $\left.6.9 \pm 2.8^{\circ}, p<0.001\right)$.

\section{Complications}

The incidence of PJK was $30.4 \%$ in the whole group; similar values were found in the OLIF51 and TLIF51 groups $(31.0 \%$ and $30.0 \%)$. However, PJK occurred

Table 2 Radiological parameters

\begin{tabular}{|c|c|c|c|c|c|c|}
\hline & \multicolumn{4}{|c|}{ Before surgery } & \multicolumn{2}{|c|}{24 months after surgery } \\
\hline & Whole & OLIF51 & TLIF51 & Whole & OLIF51 & TLIF51 \\
\hline SVA (mm) & $125.7 \pm 21.1$ & $125.9 \pm 21.3$ & $125.5 \pm 22.1$ & $29.5 \pm 14.8^{\ddagger}$ & $27.1 \pm 11.4$ & $32.7 \pm 18.4$ \\
\hline PT $\left(^{\circ}\right)$ & $33.0 \pm 7.2$ & $31.4 \pm 7.2$ & $35.1 \pm 7.0$ & $18.1 \pm 5.7^{\ddagger}$ & $17.6 \pm 4.6$ & $18.6 \pm 7.6$ \\
\hline $\mathrm{PI}\left({ }^{\circ}\right)$ & $53.7 \pm 6.4$ & $53.2 \pm 6.0$ & $54.4 \pm 7.1$ & $53.6 \pm 6.5$ & $53.0 \pm 6.0$ & $54.4 \pm 7.2$ \\
\hline LL $\left(^{\circ}\right)$ & $18.2 \pm 9.0$ & $16.7 \pm 10.4$ & $20.3 \pm 6.8$ & 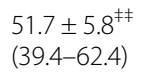 & $\begin{array}{l}55.5 \pm 2.8^{* * *} \\
(50.0-62.4)\end{array}$ & $\begin{array}{l}46.9 \pm 5.2 \\
(39.4-52.6)\end{array}$ \\
\hline LLL $\left(^{\circ}\right)$ & $9.5 \pm 4.0$ & $9.0 \pm 4.6$ & $10.2 \pm 3.3$ & $27.2 \pm 4.8^{\ddagger \neq}$ & $31.1 \pm 1.4^{* * *}$ & $22.3 \pm 2.4$ \\
\hline LLL/LL (\%) & $49.4 \pm 17.4$ & $47.5 \pm 18.2$ & $51.9 \pm 17.0$ & $52.5 \pm 5.5$ & $56.2 \pm 2.1^{* * *}$ & $47.8 \pm 4.9$ \\
\hline PI-LL $\left(^{\circ}\right)$ & $35.5 \pm 9.4$ & $36.5 \pm 8.5$ & $34.1 \pm 10.6$ & $\begin{array}{l}5.3 \pm 3.6^{\ddagger \neq} \\
(1.0-10.6)\end{array}$ & $\begin{array}{l}3.6 \pm 3.0^{* *} \\
(1.0-10.6)\end{array}$ & $\begin{array}{l}7.5 \pm 3.2 \\
(3.5-10.0)\end{array}$ \\
\hline dSVA (mm) & - & - & - & $\begin{array}{l}96.2 \pm 23.4 \\
(55.3-141.5)\end{array}$ & $98.9 \pm 22.9$ & $92.8 \pm 24.8$ \\
\hline $\mathrm{dLL}\left({ }^{\circ}\right)$ & - & - & - & $\begin{array}{l}33.4 \pm 11.5 \\
(10.0-67.5)\end{array}$ & $\begin{array}{l}38.7 \pm 10.2^{* *} \\
(32.3-67.5)\end{array}$ & $\begin{array}{l}26.6 \pm 9.8 \\
(10.0-39.9)\end{array}$ \\
\hline \multicolumn{7}{|l|}{ Mean DA $\left(^{\circ}\right)$} \\
\hline L2-L5 & $4.1 \pm 3.5$ & $3.4 \pm 4.1$ & $5.0 \pm 2.4$ & $\begin{array}{l}12.4 \pm 1.5^{\text {抹 }} \\
(8.1-16.7)\end{array}$ & $12.5 \pm 1.6$ & $12.3 \pm 1.4$ \\
\hline L5-S1 & $8.7 \pm 3.5$ & $9.8 \pm 3.6$ & $7.5 \pm 2.3$ & $\begin{array}{l}12.9 \pm 6.7^{\ddagger} \\
(3.5-27.9)\end{array}$ & $\begin{array}{l}18.4 \pm 3.7^{* * *} \\
(14.5-27.9)\end{array}$ & $\begin{array}{l}6.9 \pm 2.8 \\
(3.5-10.7)\end{array}$ \\
\hline
\end{tabular}

OLIF oblique lateral interbody fusion, TLIF transforaminal lumbar interbody fusion, SVA sagittal vertical axis, TK thoracic kyphosis, $P T$ pelvic tilt, $P$ p pelvic incidence, LL lumbar lordosis at L1-S1, LLL lumbar lordosis at L4-S1, LLL/LL LLL/LL × $100(\%)$, dSVA difference between pre- and postoperative values of SVA, dLL difference between pre- and postoperative values of $\mathrm{LL}, D A$ disc angle

$\neq p<0.01$ and $\neq \neq p<0.001$ compared to before surgery, ${ }^{* *} p<0.01$ and ${ }^{* * *} p<0.001$ compared to TLIF51 group No significant difference in the preoperative values between the TLIF51 and OLIF51 groups 
significantly earlier postoperatively in the OLIF51 than in the TLIF51 group $(8.6 \pm 1.9$ vs. $26.3 \pm 4.7$ months, $p<0.001$, Table 3).

Psoas symptoms (8/23), ileus (13/23), and leg dysesthesia $(5 / 23)$ were noted postoperatively. Postoperative ileus occurred more frequently in the OLIF51 (10/ 13) than in the TLIF51 group $(3 / 10)(p<0.05)$. There were no major complications.

\section{Intraobserver and interobserver reliabilities}

Both intraobserver and interobserver reliabilities were within acceptable ranges (0.85-0.92 and 0.75-0.83, respectively).

\section{Discussion}

The recent concept of cMIS is a combination of MIS lumbar interbody fusion and percutaneous fixation without osteotomy [3,5-8]. Previously, cMIS was not indicated for sagittal correction of ASD [7, 14, 25, 26]. Recent studies reported that cMIS could be indicated only for mild deformity, but osteotomies were required for marked deformity [4, 5]. However, according to our study, cMIS also seems to be effective for sagittal correction even in patients with marked deformity.

A ceiling effect is referred to as the maximum correction of sagittal parameters allowed by deformity surgery [16, 26]. Anand et al. reported that the ceiling effect of dSVA was $120 \mathrm{~mm}$ for cMIS [16]. In our study, the maximum dSVA was $141.5 \mathrm{~mm}$, which was greater than that previously reported. Other studies reported the maximum $\mathrm{dLL}$ and corrected LL by cMIS were $23^{\circ}$ and $54^{\circ}$, respectively $[25,26]$. In our study, the maximum dLL and corrected LL were $67.5^{\circ}$ and $62.4^{\circ}$, respectively, which were also greater than those of previous reports. Due to the increased angle correction, the postoperative sagittal parameters satisfied the surgical goals in our study. The greater LL correction in our study seemed to be related to the combination of OLIF with high-angle cages placed anteriorly in the disc space, PPSF with aggressively contoured rods, and intraoperative lumbar extension with a motorized operation table followed by percutaneous rod compression. Our study is the first to show successful correction of marked sagittal deformity with cMIS in ASD.

The mean postoperative LL was $51.7^{\circ}$ in the whole group, which might suffice for most of the Korean population whose mean PI is relatively lower $\left(47.8^{\circ}\right)$ than the western population $\left(50.2^{\circ}-52.0^{\circ}\right)$ [27-30]. The mean postoperative LL was greater in the OLIF51 than in the TLIF51 group, while the mean postoperative LL in the TLIF51 group was similar to those of other studies using DLIF at lumbar levels and TLIF or AxiaLIF at L5-S1 [12, 25]. The greater mean postoperative LL in the OLIF51 group than in the TLIF51 group seemed to be due to the significant increase in disc angle at the L5-S1 level because the L5-S1 level contributes largely to the lumbar lordosis [31]. During OLIF at L5-S1, the anterior disc space was opened widely as in anterior lumbar interbody fusion (ALIF), which helped to create a larger disc angle than that with TLIF [32-34]. Since TLIF was introduced in 1982, it was developed as a MIS technique $[12,33]$. We had been mainly used TLIF at L5-S1 level before the introduction of OLIF51. Bilateral facetectomy and TLIF with banana-shaped cages were previously reported to increase segmental angles $[35,36]$. However, there may be some debates because other studies observed no significant improvement in segmental angles after TLIF and no difference according to the TLIF cage type [32, 33].

Hybrid surgery is known to be more effective than cMIS in sagittal correction, with the drawbacks of increased operating time and EBL [7, 12, 25, 37]. However, the sagittal correction, operating time, and EBL in our study were better than those in other cMIS and hybrid surgery studies even though our patients had worse sagittal deformity preoperatively (Table 4). These better results seem to be related to OLIF use

Table 3 Proximal junctional kyphosis and rod fracture

\begin{tabular}{llll}
\hline & Whole group & OLIF51 group & TLIF51 group \\
\hline Number of PJK & $7(30.4 \%)$ & $4(31.0 \%)$ & $3(30.0 \%)$ \\
Onset (postop months) & $16.1 \pm 10.0$ & $8.6 \pm 1.9(7-10)^{* * *}$ & $26.3 \pm 4.7(21-30)$ \\
$\quad$ Cause of PJK & & & 3 \\
$\quad$ Adjacent fracture & 7 & 2 & 1 \\
$\quad$ Screw loosening & 3 & 1 & 1 \\
Management & & 2 & 2 \\
$\quad$ Revision surgery & 2 & 2 & 2 \\
$\quad$ Vertebroplasty & 4 & & 2
\end{tabular}


Table 4 Summary of our data and literature using lateral interbody fusion for correction of adult spinal deformity

\begin{tabular}{|c|c|c|c|c|c|c|}
\hline & Wang et al. [25] & Haque et al. [37] & Wang et al. [26] & Park et al. [12] & Theologis et al. [7] & Our study \\
\hline No. patients & 23 & 48 & 43 & 43 & 16 & 23 \\
\hline Deformity surgery & cMIS & cMIS & cMIS & CMIS & Hybrid & CMIS \\
\hline Fusion at L1-5 & DLIF, TLIF & LLIF, TLIF, ALIF & XLIF, TLIF & DLIF, TLIF & LLIF & OLIF \\
\hline Fusion at L5-S1 & TLIF & NS & TLIF & AxiaLIF & TLIF, ALIF & TLIF, OLIF \\
\hline Posterior fixation & PPSF & PPSF & PPSF & PPSF & OPSF & PPSF \\
\hline Fusion levels & $3.7 \pm 1.3$ & $4.7 \pm 2.8$ & $3-7$ & $4.0 \pm 1.1$ & $4.6 \pm 1.1$ & $4.4 \pm 0.5$ \\
\hline Operating time (min) & $402.0 \pm 122.3$ & $462.0 \pm 177.0$ & 479 & $452.4 \pm 212.2$ & $859.1 \pm 194.8$ & $345.0 \pm 50.0$ \\
\hline EBL (ml) & $477.4 \pm 673.5$ & $507.0 \pm 841.0$ & 585 & $552.4 \pm 460.1$ & $2460.0 \pm 1405.2$ & $331.3 \pm 109.6$ \\
\hline \multicolumn{7}{|l|}{ Preoperative } \\
\hline SVA (mm) & NR & 33.0 & $29.0 \pm 41.4$ & $30.0 \pm 54.1$ & $62.7 \pm 50.8$ & $125.7 \pm 21.1$ \\
\hline $\operatorname{LL}\left({ }^{\circ}\right)$ & 37.4 & 33.8 & $34.0 \pm 10.9$ & $41.2 \pm 15.6$ & $26.6 \pm 22.6$ & $18.2 \pm 9.0$ \\
\hline PI-LL & NR & 21.6 & NR & $10.2 \pm 15.6$ & $23.4 \pm 22.0$ & $35.5 \pm 9.4$ \\
\hline \multicolumn{7}{|l|}{ Postoperative } \\
\hline SVA & NR & 32.7 & $29.7 \pm 44.6$ & $32.1 \pm 70.1$ & $35.8 \pm 41.9$ & $29.5 \pm 14.8$ \\
\hline dSVA & NR & -0.3 & -0.7 & -2.1 & 26.9 & $96.2 \pm 23.4$ \\
\hline LL & 45.5 & 39.4 & $39.6 \pm 12.1$ & $44.1 \pm 13.1$ & $43.2 \pm 15.6$ & $51.7 \pm 5.8$ \\
\hline$d L L$ & 12.1 & 5.6 & 5.6 & 2.9 & 16.6 & $33.4 \pm 11.5$ \\
\hline PI-LL & NR & 16.0 & NR & $8.0 \pm 14.4$ & $7.4 \pm 12.4$ & $5.3 \pm 3.6$ \\
\hline
\end{tabular}

CMIS circumferential minimally invasive surgery, Hybrid MIS + open surgery, DLIF direct lateral interbody fusion, XLIF extreme lateral interbody fusion, TLIF transforaminal lumbar interbody fusion, ALIF anterior lumbar interbody fusion, AxiaLIF axial lumbar interbody fusion, OLIF oblique lateral interbody fusion, PPSF percutaneous posterior spine fusion, OPSF open posterior spine fusion, EBL estimated blood loss, PI pelvic incidence, LL lumbar lordosis at L1-S1, dSVA difference between pre- and postoperative values of SVA, dLL difference between pre- and postoperative values of LL, NS not specified, NR not reported

at L5-S1, given the improved results in the OLIF51 than in the TLIF51 group. TLIF and axial lumbar interbody fusion (AxiaLIF) for cMIS or ALIF for the hybrid surgery were the fusion techniques used at L5-S1 previously. Our study is also the first report evaluating the effects of OLIF at L5-S1 on sagittal deformity correction.

Significantly earlier PJK onset was observed in the OLIF51 group (8.6 months) than in the TLIF51 group (26.3 months), which was also earlier than that of previous reports (18.6-34.8 months) [38, 39]. Other reports found that the incidence of PJK could be reduced by minimally invasive lumbar interbody fusion and percutaneous fixation, which suggests that other factors may have accelerated PJK development after cMIS with OLIF at L5-S1 in our study [40, 41]. Faundez et al. reported an exaggerated upper lumbar lordosis resulting in junctional failure [39]. Previous studies reported that the ideal LLL/LL was $50-80 \%$ $[30,42]$. According to our data, the LLL/LL of the OLIF51 group was within the ideal range. However, there was a lordotic curve at the thoracolumbar junction, which showed similar effect of exaggerated upper lumbar lordosis. The lordotic angle at the thoracolumbar junction related with the lordotic curve of the proximal rod (Fig. 1). The lordotic curve of the proximal rod was necessary to pass a long rod percutaneously through the lumbosacral curvature. However, it resulted in increased lordosis at the thoracolumbar junction, which might lead to early PJK. Postoperatively smaller SVA, higher LL correction, and smaller PI-LL in the OLIF51 group also seemed to contribute to earlier PJK onset $[38,43]$.

The retrospective design is the major limitation of this study. Although the follow-up period was at least 2 years, a larger number of patients and longer follow-up is necessary because correcting marked sagittal deformity using cMIS is a relatively new trial. Multicenter studies performing similar cMIS are therefore needed. We suggested several factors responsible for the improved correction of marked sagittal deformity, but other mechanisms should be further investigated. Rigid deformity itself was not evaluated in this study, but we could not rule out completely the effect of rigid joints on the sagittal correction by cMIS. Considering that early PJK in the OLIF51 group is associated with exaggerated proximal lordosis, we tried to reduce it by making a kyphotic angle at the proximal rods (data not presented), but still do not know the exact underlying cause because the preventive effects can only be observed after a longer period. Our results cannot be applied for adolescent idiopathic scoliosis because we studied only for ASD. 


\section{Conclusions}

According to our data, the use of OLIF with cMIS seemed to help to overcome the main limitation of cMIS in correcting marked sagittal deformity of ASD. Although OLIF at L5-S1 showed a synergistic effect on the sagittal correction with cMIS, early PJK remained an unsolved issue of cMIS using OLIF at L5-S1.

\begin{abstract}
Abbreviations
ASA: American Society of Anesthesiologists; ASD: Adult spinal deformity; BMD: Bone mineral density; BMI: Body mass index; cMIS: Circumferential minimally invasive surgery; DA: Disc angle; LL: Lumbar lordosis; LLL: Lower lumbar lordosis; ODI: Oswestry Disability Index; OLIF: Oblique lateral interbody fusion; PEEK: Polyether-ether ketone; PI: Pelvic incidence; PJK: Proximal junctional kyphosis; PPSF: Percutaneous posterior spine fixation; PT: Pelvic tiltSVASagittal vertebral axis; TLIF: Transforaminal lumbar interbody fusion; VAS: Visual analog scale
\end{abstract}

\section{Acknowledgements}

Not applicable.

\section{Authors' contributions}

SWP, YBK, and CLH contributed to the conceptualization and formulation. The investigation and data collection were done by SWP, MJK, and YBK. SWP and MJK carried out the statistical analysis. The study was performed under supervision of YBK. All authors read and approved the final manuscript.

\section{Funding}

None.

\section{Availability of data and materials}

The datasets used during the current study are available from the corresponding author upon reasonable request.

\section{Ethics approval and consent to participate}

This study was approved by the institutional review board of Chung-Ang University Hospital (approval number: 1810-014-16217). The need for informed consent was waived because this study was a retrospective crosssectional study.

\section{Consent for publication}

Not applicable.

\section{Competing interests}

The authors declare that they have no competing interests.

\section{Author details}

'Department of Neurosurgery, College of Medicine, Chung-Ang University, 102 Heukseok-ro, Dongjak-gu, Seoul 06973, Republic of Korea. ${ }^{2}$ Head Department of Orthopedic surgery, Polyclinique Bordeaux Nord Aquitaine, 15-35 Rue Claude Boucher, 33300 Bordeaux, France.

Received: 23 July 2019 Accepted: 5 January 2020

Published online: 15 January 2020

\section{References}

1. Okuda S, Miyauchi A, Oda T, Haku T, Yamamoto T, Iwasaki M. Surgical complications of posterior lumbar interbody fusion with total facetectomy in 251 patients. J Neurosurg Spine. 2006;4:304-9.

2. Glassman SD, Hamill CL, Bridwell KH, Schwab FJ, Dimar JR, Lowe TG. The impact of perioperative complications on clinical outcome in adult deformity surgery. Spine (Phila Pa 1976). 2007;32:2764-70.

3. Mundis GM, Akbarnia BA, Phillips FM. Adult deformity correction through minimally invasive lateral approach techniques. Spine (Phila Pa 1976). 2010; 35:S312-21.

4. Anand N. How to create sagittal balance in MIS correction of adult spinal deformity. Spine (Phila Pa 1976). 2017;42(Suppl 7):S17-8.

5. Mummaneni PV, Shaffrey Cl, Lenke LG, Park P, Wang MY, La Marca F, Smith JS, Mundis GM Jr, Okonkwo DO, Moal B, et al. The minimally invasive spinal deformity surgery algorithm: a reproducible rational framework for decision making in minimally invasive spinal deformity surgery. Neurosurg Focus. 2014;36:E6.

6. Yen CP, Mosley Yl, Uribe JS. Role of minimally invasive surgery for adult spinal deformity in preventing complications. Curr Rev Musculoskelet Med. 2016:9:309-15.

7. Theologis AA, Mundis GM Jr, Nguyen S, Okonkwo DO, Mummaneni PV, Smith JS, Shaffrey Cl, Fessler R, Bess S, Schwab F, et al. Utility of multilevel lateral interbody fusion of the thoracolumbar coronal curve apex in adult deformity surgery in combination with open posterior instrumentation and L5-S1 interbody fusion: a case-matched evaluation of 32 patients. J Neurosurg Spine. 2017;26:208-19.

8. Strom RG, Bae J, Mizutani J, Valone F 3rd, Ames CP, Deviren V. Lateral interbody fusion combined with open posterior surgery for adult spinal deformity. J Neurosurg Spine. 2016:25:697-705.

9. Schwender JD, Holly LT, Rouben DP, Foley KT. Minimally invasive transforaminal lumbar interbody fusion (TLIF): technical feasibility and initial results. J Spinal Disord Tech. 2005;18(Suppl):S1-6.

10. Woods KR, Billys JB, Hynes RA. Technical description of oblique lateral interbody fusion at L1-L5 (OLIF25) and at L5-S1 (OLIF51) and evaluation of complication and fusion rates. Spine J. 2017:17:545-53.

11. Anand N, Baron EM, Thaiyananthan G, Khalsa K, Goldstein TB. Minimally invasive multilevel percutaneous correction and fusion for adult lumbar degenerative scoliosis: a technique and feasibility study. J Spinal Disord Tech. 2008;21:459-67.

12. Park P, Wang MY, Lafage V, Nguyen S, Ziewacz J, Okonkwo DO, Uribe JS, Eastlack RK, Anand N, Haque R, et al. Comparison of two minimally invasive surgery strategies to treat adult spinal deformity. J Neurosurg Spine. 2015; 22:374-80.

13. Than KD, Park P, Fu KM, Nguyen S, Wang MY, Chou D, Nunley PD, Anand N, Fessler RG, Shaffrey $\mathrm{Cl}$, et al. Clinical and radiographic parameters associated with best versus worst clinical outcomes in minimally invasive spinal deformity surgery. J Neurosurg Spine. 2016;25:21-5.

14. Kanter AS, Tempel ZJ, Ozpinar A, Okonkwo DO. A review of minimally invasive procedures for the treatment of adult spinal deformity. Spine (Phila Pa 1976). 2016:41(Suppl 8):S59-65.

15. Mundis GM Jr, Turner JD, Deverin V, Uribe JS, Nunley $P$, Mummaneni $P$, Anand N, Park P, Okonkwo DO, Wang MY, et al. A critical analysis of sagittal plane deformity correction with minimally invasive adult spinal deformity surgery: a 2-year follow-up study. Spine Deform. 2017:5:265-71.

16. Anand N, Cohen JE, Cohen RB, Khandehroo B, Kahwaty S, Baron E. Comparison of a newer versus older protocol for circumferential minimally invasive surgical (CMIS) correction of adult spinal deformity (ASD)-evolution over a 10-year experience. Spine Deform. 2017;5:213-23.

17. Uribe JS, Deukmedjian AR, Mummaneni PV, Fu KM, Mundis GM Jr, Okonkwo DO, Kanter AS, Eastlack R, Wang MY, Anand N, et al. Complications in adult spinal deformity surgery: an analysis of minimally invasive, hybrid, and open surgical techniques. Neurosurg Focus. 2014;36:E15

18. Anand N, Kong C, Fessler RG. A staged protocol for circumferential minimally invasive surgical correction of adult spinal deformity. Neurosurgery. 2017:81:733-9.

19. Schwab F, Ungar B, Blondel B, Buchowski J, Coe J, Deinlein D, DeWald C, Mehdian H, Shaffrey C, Tribus C, Lafage V. Scoliosis Research SocietySchwab adult spinal deformity classification: a validation study. Spine (Phila Pa 1976). 2012;37:1077-82.

20. Kyrola K, Repo J, Mecklin JP, Ylinen J, Kautiainen H, Hakkinen A. Spinopelvic changes based on the simplified SRS-Schwab Adult Spinal Deformity Classification: relationships with disability and health-related quality of life in adult patients with prolonged degenerative spinal disorders. Spine (Phila Pa 1976). 2018:43:497-502.

21. Savage JW, Patel AA. Fixed sagittal plane imbalance. Global Spine J. 2014;4: 287-96.

22. Lafage V, Schwab F, Patel A, Hawkinson N, Farcy JP. Pelvic tilt and truncal inclination: two key radiographic parameters in the setting of adults with spinal deformity. Spine (Phila Pa 1976). 2009;34:E599-606.

23. Glattes RC, Bridwell KH, Lenke LG, Kim YJ, Rinella A, Edwards C 2nd. Proximal junctional kyphosis in adult spinal deformity following long instrumented posterior spinal fusion: incidence, outcomes, and risk factor analysis. Spine (Phila Pa 1976). 2005;30:1643-9.

24. Shrout PE, Fleiss JL. Intraclass correlations: uses in assessing rater reliability. Psychol Bull. 1979;86:420-8. 
25. Wang MY, Mummaneni PV. Minimally invasive surgery for thoracolumbar spinal deformity: initial clinical experience with clinical and radiographic outcomes. Neurosurg Focus. 2010;28:E9.

26. Wang MY, Mummaneni PV, Fu KM, Anand N, Okonkwo DO, Kanter AS, La Marca F, Fessler R, Uribe J, Shaffrey Cl, et al. Less invasive surgery for treating adult spinal deformities: ceiling effects for deformity correction with 3 different techniques. Neurosurg Focus. 2014;36:E12.

27. Lee CS, Chung SS, Kang KC, Park SJ, Shin SK. Normal patterns of sagittal alignment of the spine in young adults radiological analysis in a Korean population. Spine (Phila Pa 1976). 2011;36:E1648-54.

28. Gangnet N, Dumas R, Pomero V, Mitulescu A, Skalli W, Vital JM. Threedimensional spinal and pelvic alignment in an asymptomatic population. Spine (Phila Pa 1976). 2006;31:E507-12.

29. Lafage V, Schwab F, Skalli W, Hawkinson N, Gagey PM, Ondra S, Farcy JP. Standing balance and sagittal plane spinal deformity: analysis of spinopelvic and gravity line parameters. Spine (Phila Pa 1976). 2008;33:1572-8.

30. Le Huec JC, Hasegawa K. Normative values for the spine shape parameters using 3D standing analysis from a database of 268 asymptomatic Caucasian and Japanese subjects. Eur Spine J. 2016;25:3630-7.

31. Kim JY, Park JY, Kim KH, Kuh SU, Chin DK, Kim KS, Cho YE. Minimally invasive transforaminal lumbar interbody fusion for spondylolisthesis: comparison between isthmic and degenerative spondylolisthesis. World Neurosurg. 2015;84:1284-93.

32. Hsieh PC, Koski TR, O'Shaughnessy BA, Sugrue P, Salehi S, Ondra S, Liu JC. Anterior lumbar interbody fusion in comparison with transforaminal lumbar interbody fusion: implications for the restoration of foraminal height, local disc angle, lumbar lordosis, and sagittal balance. J Neurosurg Spine. 2007;7: 379-86.

33. Choi WS, Kim JS, Hur JW, Seong JH. Minimally invasive transforaminal lumbar interbody fusion using banana-shaped and straight cages: radiological and clinical results from a prospective randomized clinical trial. Neurosurgery. 2018:82:289-98.

34. Watkins RG, Hanna R, Chang D, Watkins RG 3rd. Sagittal alignment after lumbar interbody fusion: comparing anterior, lateral, and transforaminal approaches. J Spinal Disord Tech. 2014;27:253-6.

35. Lindley TE, Viljoen SV, Dahdaleh NS. Effect of steerable cage placement during minimally invasive transforaminal lumbar interbody fusion on lumbar lordosis. J Clin Neurosci. 2014;21:441-4.

36. Kim JT, Shin MH, Lee HJ, Choi DY. Restoration of lumbopelvic sagittal alignment and its maintenance following transforaminal lumbar interbody fusion (TLIF): comparison between straight type versus curvilinear type cage. Eur Spine J. 2015;24:2588-96.

37. Haque RM, Mundis GM Jr, Ahmed Y, El Ahmadieh TY, Wang MY, Mummaneni PV, Uribe JS, Okonkwo DO, Eastlack RK, Anand N, et al. Comparison of radiographic results after minimally invasive, hybrid, and open surgery for adult spinal deformity: a multicenter study of 184 patients. Neurosurg Focus. 2014;36:E13.

38. Maruo K, Ha Y, Inoue S, Samuel S, Okada E, Hu SS, Deviren V, Burch S, William $S$, Ames CP, et al. Predictive factors for proximal junctional kyphosis in long fusions to the sacrum in adult spinal deformity. Spine (Phila Pa 1976). 2013;38:E1469-76.

39. Faundez AA, Richards J, Maxy P, Price R, Leglise A, Le Huec JC. The mechanism in junctional failure of thoraco-lumbar fusions. Part II: analysis of a series of PJK after thoraco-lumbar fusion to determine parameters allowing to predict the risk of junctional breakdown. Eur Spine J. 2018; 27(Suppl 1):139-48.

40. Bae J, Theologis AA, Strom R, Tay B, Burch S, Berven S, Mummaneni PV, Chou D, Ames CP, Deviren V. Comparative analysis of 3 surgical strategies for adult spinal deformity with mild to moderate sagittal imbalance. J Neurosurg Spine. 2018;28:40-9.

41. Mummaneni PV, Park P, Fu KM, Wang MY, Nguyen S, Lafage V, Uribe JS, Ziewacz J, Terran J, Okonkwo DO, et al. Does minimally invasive percutaneous posterior instrumentation reduce risk of proximal junctional kyphosis in adult spinal deformity surgery? A propensity-matched cohort analysis. Neurosurgery. 2016;78:101-8.

42. Yilgor C, Sogunmez N, Boissiere L, Yavuz Y, Obeid I, Kleinstuck F, PerezGrueso FJS, Acaroglu E, Haddad S, Mannion AF, et al. Global Alignment and Proportion (GAP) score: development and validation of a new method of analyzing spinopelvic alignment to predict mechanical complications after adult spinal deformity surgery. J Bone Joint Surg Am. 2017:99:1661-72
43. Lafage R, Bess S, Glassman S, Ames C, Burton D, Hart R, Kim HJ, Klineberg E, Henry J, Line B, et al. Virtual modeling of postoperative alignment after adult spinal deformity surgery helps predict associations between compensatory spinopelvic alignment changes, overcorrection, and proximal junctional kyphosis. Spine (Phila Pa 1976). 2017;42:E1119-25.

\section{Publisher's Note}

Springer Nature remains neutral with regard to jurisdictional claims in published maps and institutional affiliations.
Ready to submit your research? Choose BMC and benefit from:

- fast, convenient online submission

- thorough peer review by experienced researchers in your field

- rapid publication on acceptance

- support for research data, including large and complex data types

- gold Open Access which fosters wider collaboration and increased citations

- maximum visibility for your research: over $100 \mathrm{M}$ website views per year

At $\mathrm{BMC}$, research is always in progress.

Learn more biomedcentral.com/submissions 